\title{
Techniques Used for Metals' Analysis of Organic Compounds in Wastewater, Greywater and Rainwater: A Brief Review
}

\author{
Vinícius Silva dos Santos ${ }^{1 *}$, Lilian Lefol Nani Guarieiro ${ }^{1}$ \\ ${ }^{1}$ Senai Cimatec University Center; Salvador, Bahia, Brazil
}

\begin{abstract}
Water recycling is a sustainable way of managing water resources because of the large consumption of fresh water in the world caused by population growth, urbanization, and industrial development. However, the reuse of freshwater requires serious care due to the appearance of contaminants after its use, such as active chemicals, micropollutants, and pharmaceutical products. This study presents a systematic review of articles that includes terms of techniques used to assess metals and organic compounds in wastewater samples (a combination of effluents and water originated from bathrooms, showers, and kitchen sinks, and rainwater between the years 2000 and 2020).

Keywords: Systematic Review. Characterization. Wastewater. Greywater. Rainwater.

Abbreviations: PAHs: polycyclic aromatic hydrocarbons; ICP OES: inductively coupled plasma optical emission spectrometry; SBSE: sorting stir bar extraction; GC-MS: gas chromatography coupled to mass spectrometry; GC-ECD: gas chromatography-electron capture detector; SPME -HPLC-UV: solid phase microextraction with detection by high performance liquid chromatography; ICP MS: inductively coupled plasma mass spectrometry; AAS: atomic absorption spectrometry; F AAS: flame atomic absorption spectrometry; GF AAS: graphite furnace atomic absorption spectrometry; HG AAS: hydride generation coupled to atomic absorption spectrometry, CV AAS: cold vapor atomic absorption spectrometry; DGT: gradient in the thin films; DPASV: differential pulse anodic stripping voltammetry; FIA: flow injection analysis; CLE-ACSV: competitive ligand exchangeadsorptive cathodic stripping voltammetry; DPCSV: differential pulse cathodic stripping voltammetry; SIA: sequential injection analysis; XRF: X-ray fluorescence; HPLC: high performance liquid chromatography; HTC: high temperature combustion; FT-ICR MS: cyclotron ion resonance mass spectrometry by ESI Fourier transformation; HPLC-DAD: liquid chromatography coupled to a photodiode matrix detector; LC-APCI-MS: chemical ionization ions by atmospheric pressure; LC-MS/MS: liquid chromatography coupled to two mass spectrometers; GC-FTD: thermoionic flame detector.
\end{abstract}

\section{Introduction}

Freshwater consumption is increasing worldwide due to the acceleration of population growth, followed by urbanization and industrial development [1]. Water resources have been exploited throughout history, which has generated water pollution, making it useless for humans. This increase in water demand is linked to some processes such as climate change and river

Received on 18 September 2020; revised 16 December 2020. Address for correspondence: Vinícius Silva dos Santos. SENAI CIMATEC - Centro Integrado de Manufatura e Tecnologia, Avenida Orlando Gomes, Número 1845 - Piatã, Zip Code: 41650-010, Salvador, Bahia, Brazil, phone: +55 (71) 992517119. E-mail: santoss.vinicius96@gmail. com. Article selected from VI International Symposium on Innovation and Technology (SIINTEC).

J Bioeng. Tech. Appl. Health 2021;4(1):37-.42

(C) 2021 by SENAI CIMATEC. All rights reserved. pollution [1-3]. Agriculture, dams, and changes in land use are also reshaping the rate, expansion, and distribution of consumption and replenishment of freshwater [4].

One of the sustainable solutions in the management of water resources is the recycling of wastewater. The treatment of wastewater in the 20th century highlighted the theme of protecting public health, reducing pollution, and preventing environmental degradation [4]. On the other hand, wastewater consumption can affect human health due to the presence of active chemicals and endocrine disruptors, micropollutants, including pharmaceuticals and personal care products, PAHs, phosphorus flame retardants, plasticizers, pesticides, and pathogens. Additionally, other factors that ultimately affect human health are soil quality due to accumulation of salinity and toxic metals, as the contamination of groundwater by salts, and the quality of crops $[2,5,6,7]$. 
There are also alternative sources for nonpotable supply, with emphasis on the use of rainwater and greywater. Greywater can be defined as wastewater originating from bathrooms, showers, washbasins, washing machines and tanks, and kitchen sinks [8].

The origin and destination of these waters and their characterization is important for public health. The analysis that one can be sure that the water distributed is reliable if it is free of microorganisms or harmful chemicals to human health and the environment.

Park and colleagues (2009) [9] examined the effects of $\gamma$-ray treatment on wastewater toxicity at a rubber plant in Korea using Daphnia magna, a small planktonic crustacean that belongs to the Phyllopoda subclass. ICP OES was used to analyze $\mathrm{Al}, \mathrm{Cd}, \mathrm{Cu}, \mathrm{Cr}, \mathrm{Fe}, \mathrm{Pb}$, and $\mathrm{Zn}$. The results showed the gamma-ray treatment did not completely remove the toxicity of wastewater and effluents from a rubber factory, suggesting that the main toxic agents were probably cationic metals [9].

Pang and colleagues (2016) [10] used an SBSE with chemical derivatization to preconcentrate 29 biogenic carbonyl compounds in rainwater samples in Yor, United Kingdom. For the detection and quantification of species, they used GC-MS. The sensitivity of the method using SBSE was evaluated in terms of LOD. The SBSE LODs of the 29 species studied ranged from 0.02 to 0.24 $\mu \mathrm{g} / \mathrm{L}$. The LODs of the SBSE-GC-MS technique for carbonyl measurements employed in this work were lower than those of GC-ECD and SPME -HPLC-UV [10].

So, the following work aimed to carry out a systematic review on the main techniques used for the assessment of metals and organic compounds in wastewater, greywater, and rainwater, highlighting the journals with the largest number of articles, the countries that most published about this subject, the years with the largest number of publications 2000 and 2020, and the most applied techniques between the years.

\section{Material and Methods}

To find the techniques used for the evaluation of chemical compounds in different types of wastewater, gray water, and rainwater, a systematic review was used in four databases: Science Direct (https://www.sciencedirect. com" https://www. sciencedirect.com), Web of Science (https:// www.webofknowledge.com/" https://www. webofknowledge.com/), Scopus (https://www. scopus.com/home.uri" https:// www.scopus.com/home.uri) and Scielo (https:// www.scielo.org/" https://www.scielo.org/). To start the systematic review, search filters were selected using the keywords: wastewater; gray waters; rainwater; metals; organic compounds. The research focused on the period between 2000 and 2020.

\section{Results and Discussion}

The application of the systematic review resulted in 83 studies found according to the established filters. Table 1 shows the number of publications found for each investigated database. The works were found in 41 scientific journals, among which the "Atmospheric Environment" stood out with 7 published articles, followed by "Revista Brasileira de Engenharia Agrícola e Ambiental " and "Water Research" with 6 articles published in each journal.

Table 1. Number of publications found for each database.

\begin{tabular}{lc}
\hline Database & Number of publications \\
\hline Science Direct & 20 \\
Web of Science & 33 \\
Scopus & 17 \\
Scielo & 13 \\
\hline
\end{tabular}

Brazil was the country that showed the most interest in the characterization of recyclable waters (wastewater, greywater, and rainwater), 
presenting a total of 19 articles, followed by China with 8 published articles and the United States with 7 articles. Figure 1 shows the countries that published articles related to the researched topic followed by the number of publications.

Figure 2 presents the publications of the articles distributed over the years in an eventual way. The Figure 2 does not show a sequential growth in the number of publications each year, but a growth followed by a decrease each year, with a distinction of the period between the years 2008 and 2011, in which 27 articles were published (33.3\% of the 83 articles published in this period).

At least 18 techniques were used for the determination of metals in wastewater, greywater, and rainwater. The metals most frequently found in the articles were $\mathrm{Cd}, \mathrm{Cu}, \mathrm{K}, \mathrm{Na}$, and $\mathrm{Pb}$. ICP OES and ICP MS totalized 15 applications for the assessment of metals in the aforementioned waters. Jambers and colleagues used both ICP OES (detection limits 0.2-3.0 ppb; accuracy $10 \%$ ) and ICP MS (detection limits 1-100 ppt; accuracy $10 \%$ ) for the inorganic characterization of rainwater collected above the North Sea [11]. ICP based techniques have been highlighted for their versatility and detection capacity. A plasma spectrometer usually reaches a temperature of $8,000 \mathrm{~K}$ and causes a less reactive chemical environment than an atomizer flame. The high temperature determined by the plasma source

Figure 1. Countries that published on the topic.

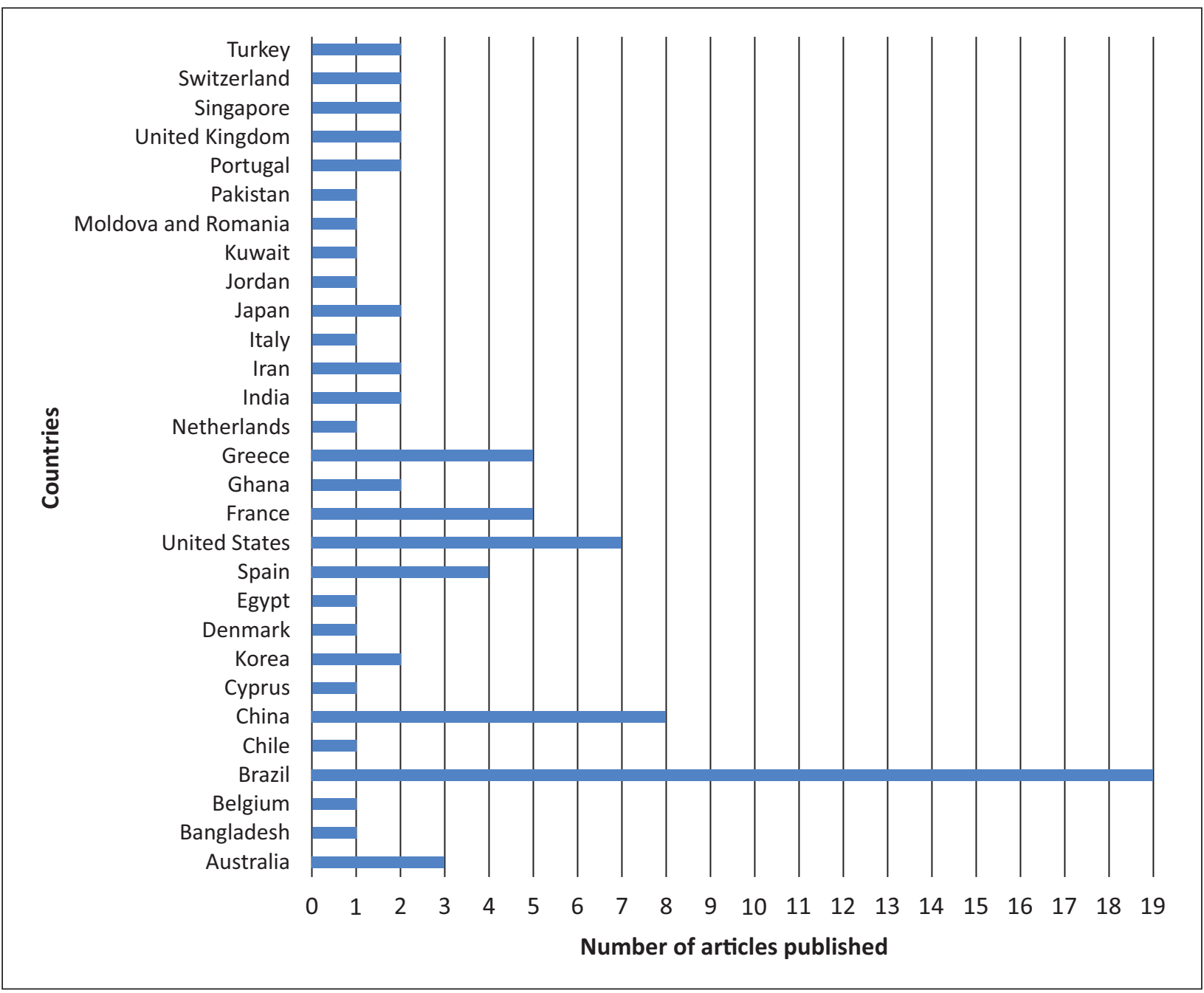


Figure 2. Number of articles published per year.

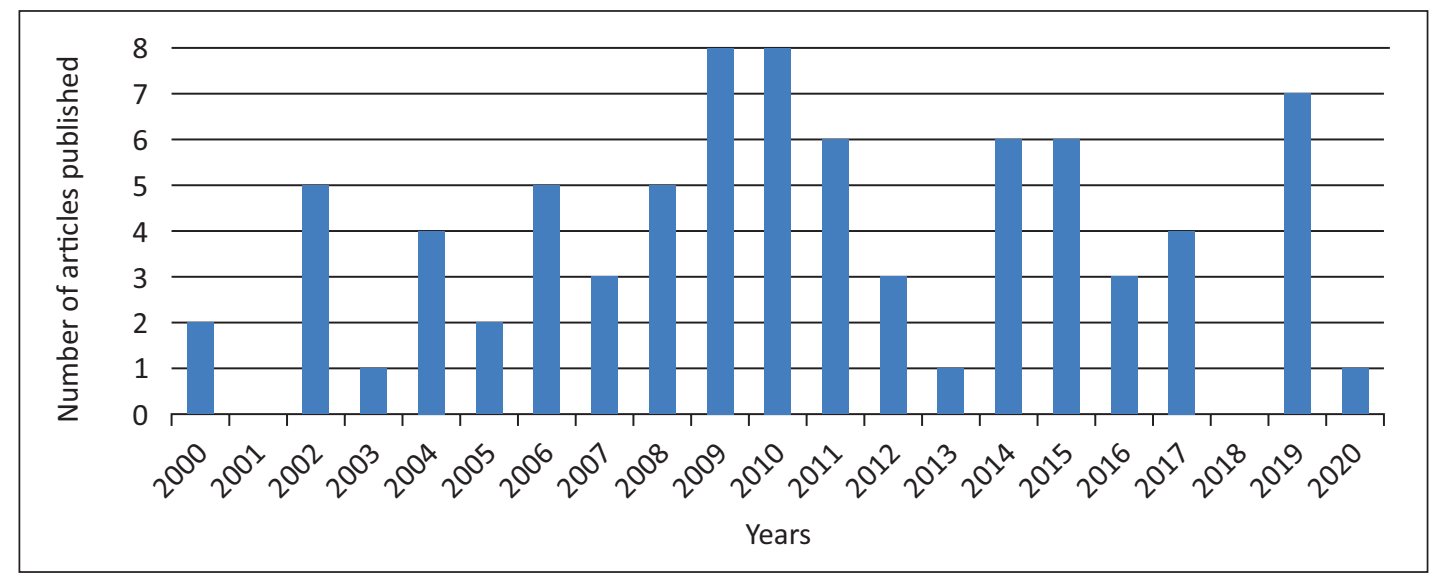

allows a highly sensitive determination of common elements detected by other analytical techniques, such as refractory metals or form refractory oxides, rare earth elements, and light elements like boron [12].

Other techniques are AAS. F AAS, GF AAS, HG AAS, and CV AAS had a sum of 18 applications. AAS, also widely used, has been compared throughout history with ICP. Its advantages compared to ICP are lower equipment and operational costs, ease of operation, and a reduced number of spectral lines, allowing less interference by overlapping lines. However, AAS has a small linear working range, less analytical frequency, and some non-metallic elements are not easily determined, such as phosphorus and sulfur, and it mainly considered a mono elementary analytical technique, its greatest disadvantage [13]. Buzier and colleagues (2006) [14] used GF AAS to determine copper and cadmium in wastewater samples after using DGT as a tool for metal speciation, concluding that DGT can be very useful to provide an operational fractionation of metals in wastewater [14].

Other techniques also used in the studies analyzed, such as flame photometry to determining sodium in gray waters [15]; ion chromatography with conductometric detection, used by Fontenele and Pedrotti to determine copper, lead, cadmium, as well as major cations and anions in rainwater samples [16]; DPASV, used by Prestes and colleagues [17] to determine copper, lead and cadmium in rainwater samples [17]; in addition to FIA with anodic stripping voltammetry detection; CLE-ACSV; atomic emission spectrophotometer with flame atomization; voltammetric determination by anodic stripping using a chitosan modified carbon paste electrode; colorimetry; titrimetry; DPCSV; infrared spectroscopy; SIA, XRF; and UV absorbance, totaling the use of 20 techniques used with different methodologies in 56 of the 83 articles found.

GC-MS has been the most used technique for the determination of organic compounds in wastewater, greywater, and rainwater in the last 20 years [18]. GC-MS applies to volatile and thermally stable compounds at the relatively high temperatures employed during the chromatographic separation process. These requirements are similar to those required for compounds to be ionized through IE and IQ2 [19]. An analytical strategy involving the use of GC-MS certainly has the advantage of enabling identification with excellent sensitivity and reproducibility for compounds that occur in complex matrices [20]. Noutsopoulos and colleagues (2017) [18] characterized greywater samples from Greek households using GC-MS according to Samaras and colleagues (2011) [21] to assess micropollutants present in the samples.

Then, the technique with the most appearances was HPLC. HPLC uses small columns, filled by a mobile phase that is eluted under high pressures. 
This technique can perform separations and quantitative analyzes of a large number of compounds present in various types of samples in a few minutes, with high resolution, efficiency, and sensitivity. Due to its characteristics, it is widely used in the pharmaceutical industry. Eschauzier and colleagues (2010) [22] used HPLC to determine perfluorinated compounds in the infiltrated water of the Rhine and rainwater infiltrated in coastal dunes.

A wide variety of organic compounds was found in the studied waters, such as recalcitrant compounds, biogenic carbonyl compounds, perfluorinated compounds, aldehydes, phenolic compounds, hydroquinones, among others.

Other techniques appeared less frequently, such as cyclic voltammetry with vitreous carbon electrode modified with bismuth film, used by Santos and colleagues [23] to determine 2,4-dinitrophenol (2,4-DNP) in rainwater from regions of Santa Catarina; in addition to UV/visible spectroscopy; fluorescence spectrophotometry; thermo-optical analyzer; HTC; capillary electrophoresis; hightemperature catalytic oxidation; FT-ICR MS; HPLC-DAD; and sources of LC-APCI-MS; LCMS/S; GCFTD, totaling the sum of 13 techniques employed with different methodologies in 42 of the 83 articles found.

\section{Conclusion}

The systematic review was able to identify a considerable amount of specific research articles from the last 20 years, making it possible to evaluate databases, journals, countries, years of publication, and techniques used for the analysis of metals and organic compounds in wastewater, greywater, and rainwater, facilitating a possible choice and future implementation of techniques for the characterization of water samples. The characterization of these waters is of paramount importance to ensure their potability, verifying their quality from different sources, reaching the standards of demand for their use.

\section{Acknowledgments}

We are grateful to the Fundação de Amparo à Pesquisa do Estado Bahia (FAPESB) for the financial support given to the research project in which this work is inserted.

\section{References}

1. Xiao S, Yan W, Hayan L, Xueqiao Y, Lei S, Xinfeng $\mathrm{W}$, et al. Organic acids in cloud water and rainwater at a mountain site in acid rain areas of South China. Environmental Science and Pollution Research 2016;23:9529-9539.

2. Francisco P, Ioannis K, Juan JA, Prodromos K, Takashi A. Use of treated municipal wastewater in irrigated agriculture-Review of some practices in Spain and Greece. Agricultural Water Management 2010;97:1233-1241.

3. Jianying $\mathrm{X}$, Dongbin $\mathrm{W}$, Feipeng $\mathrm{W}$, Chenzhong B, Yuguo D. Bioassay: A useful tool for evaluating reclaimed water safety. Journal of Environmental Sciences 2020;88:165-176.

4. Takashi A, Audrey DL. Recovering sustainable waste from wastewater. Environ Sci Technol. 2004;38:201A-208A.

5. Trent WB, Binbin J. Soil salinity and exchangeable cations in a wastewater irrigated area, India. Journal of environmental quality. 2009;38:887-896.

6. Weiping C, Sidan L, Wentao J, Meie W, Andrew CC. Reclaimed water: A safe irrigation water source? Environmental Development 2013;8:74-83.

7. Juan W, Zhe T, Yingbin H, Min Y, Xingcan Z, Yu Z. Monitoring of 943 organic micropollutants in wastewater from municipal wastewater treatment plants with secondary and advanced treatment processes. Journal of Environmental Sciences 2018;67:309-317.

8. Simone M. Caracterização, tratamento e reúso de águas cinzas e aproveitamento de águas pluviais em edificações. 2009. Tese de Doutorado. Universidade de São Paulo.

9. Park, E., et al. "Effects of gamma-ray treatment on wastewater toxicity from a rubber products factory." Journal of radioanalytical and nuclear chemistry 277.3 (2008): 619-624.

10. PANG, Xiaobing; LEWIS, Alastair C.; SHAW, Marvin D. Analysis of biogenic carbonyl compounds in rainwater by stir bar sorptive extraction technique with chemical0020derivatization and gas chromatographymass spectrometry. Journal of separation science, v. 40, n. 3, p. 753-766, 2017.

11. Jambers W, Dekov V, Van Grieken R. Single particle and inorganic characterization of rainwater collected above the North Sea. Science of the Total Environment 2000;256:133-150. 
12. Cleber GN, Marcos AB, Erik GP, Ana MP, Ivana LS, João HS. A review of multivariate designs applied to the optimization of methods based on inductively coupled plasma optical emission spectrometry (ICP OES). Microchemical Journal 2016;128:331-346.

13. Fábio Alan CA, Ivon PL, Vera Lucia CS, Sérgio Luis CF. Espectrometria de absorção atômica: o caminho para determinações multi-elementares. Quím. Nova. 2008;31:1784-1790.

14. Rémy $B$, Marie-Hélène $T$, Jean-Marie $M$. Evaluation of DGT as a metal speciation tool in wastewater. Science of the Total Environment 2006;358:277285.

15. Oteng-Peprah M, Vries NK, Acheampong MA. Greywater characterization and generation rates in a peri urban municipality of a developing country. Journal of Environmental Management 2018;206:498506.

16. Anna Paula GF, Pedrotti, Jairo JP, Adalgiza F. Avaliação de metais traços e íons majoritários em águas de chuva na cidade de São Paulo. Quím. Nova. 2009;32:839844.

17. Prestes, E. C., Anjos, V. E. D., Sodré, F. F., \& Grassi, M. T. (2006). Copper, lead and cadmium loads and behavior in urban stormwater runoff in Curitiba, Brazil. Journal of the Brazilian Chemical Society, 17(1), 5360. 17, n. 1, p. 53-60, 2006.
18. Noutsopoulos C,Andreadakis A, Kouris N, Charchousi D, Mendrinou P, Galani A et al. Greywater characterization and loadings-physicochemical treatment to promote onsite reuse. Journal of Environmental Management 2018;216:337-346.

19. Mariza CC, Carol HC, Isabel CS. O estado da arte da cromatografia associada à espectrometria de massas acoplada à espectrometria de massas na análise de compostos tóxicos em alimentos. Quím. Nova. 2008;31:623-636.

20. Maria MS, Rosario N, Francesco S, Daniele N, Anna A. GC-MS approaches for the screening of metabolites produced by marine-derived Aspergillus. Marine Chemistry 2018;206:19-33.

21. Samaras, Vasilios G., et al. "An analytical method for the simultaneous trace determination of acidic pharmaceuticals and phenolic endocrine disrupting chemicals in wastewater and sewage sludge by gas chromatography-mass spectrometry." Analytical and Bioanalytical Chemistry 399.7 2011;2549-2561.

22. Eschauzier, C., Haftka, J., Stuyfzand, P. J., de Voogt, P. Perfluorinated compounds in infiltrated river rhine water and infiltrated rainwater in coastal dunes. Environmental science \& technology, 2010;44:7450-7455.

23. Santos, M. S. D., Bianchin, J. N., Spinelli, A. Desenvolvimento de metodologia analítica baseada em eletrodo de carbono vítreo modificado com filme de bismuto: Aplicação em águas de chuva de regiões de Santa Catarina. Eclética Química. 2011;36:158-181. 